\title{
Detection and Molecular Characterization of Boscalid-Resistant Botrytis cinerea Isolates from Strawberry
}

\author{
Thomas Veloukas, Plant Pathology Laboratory, Faculty of Agriculture, Aristotelian University, Thessaloniki, Greece; Michaela \\ Leroch and Matthias Hahn, Department of Biology, University of Kaiserslautern, Germany; and George S. Karaoglanidis, Plant \\ Pathology Laboratory, Faculty of Agriculture, Aristotelian University, Thessaloniki, Greece
}

\begin{abstract}
Veloukas, T., Leroch, M., Hahn, M., and Karaoglanidis, G. S. 2011. Detection and molecular characterization of boscalid-resistant Botrytis cinerea isolates from strawberry. Plant Dis. 95:1302-1307.

Botrytis cinerea isolates $(n=122)$ were collected from strawberry fields located in northern Greece during a 3-year period (2008-10) and tested for their sensitivity to the succinate dehydrogenase inhibitor boscalid. Sensitivity measurements showed three distinct phenotypes consisting of isolates highly sensitive (fungicide concentration causing inhibition of germ tube growth by $50 \%$ [EC $\mathrm{E}_{50}$ values] of 0.05 to 0.21 $\left.\mu \mathrm{g} \mathrm{ml}^{-1}\right)$, moderately resistant $\left(\mathrm{EC}_{50}\right.$ values of 1.37 to $\left.7.79 \mu \mathrm{g} \mathrm{ml}^{-1}\right)$, or highly resistant $\left(\mathrm{EC}_{50}\right.$ values of $\left.>50 \mu \mathrm{g} \mathrm{ml}^{-1}\right)$ to boscalid. Sequence analysis of the $s d h B$ gene revealed five mutations leading to amino acid substitutions in the SdhB subunit in isolates moderately resistant and highly resistant to boscalid. Three moderately resistant isolates showed a nucleotide change from $\mathrm{A}$ to $\mathrm{T}$ at codon 230 , resulting in an asparagine to isoleucine (N230I) substitution. Several moderately resistant isolates showed a nucleotide change from $\mathrm{C}$ to $\mathrm{T}$ at codon 272 , resulting in a substitution from histidine to arginine (H272R)

was found at the same codon, leading to a substitution from histidine to tyrosine (H272Y). One highly resistant isolate had a nucleotide change from $\mathrm{A}$ to $\mathrm{T}$ at codon 272 , leading to a substitution from histidine to leucine $(\mathrm{H} 272 \mathrm{~L})$, whereas, in three other highly resistant isolates, a double nucleotide change from CC to TT was observed at codon 225, resulting in a substitution from proline to phenylalanine $(\mathrm{P} 225 \mathrm{~F})$. To facilitate rapid detection of these mutations associated with resistance to boscalid, a primer-introduced restriction analysis polymerase chain reaction was developed. The method was successfully applied to the moderately and highly resistant subpopulations and showed that the $\mathrm{H} 272 \mathrm{R}$ mutation was predominant with relative frequencies of 28.5 , 37.5 , and $30 \%$ during 2008, 2009, and 2010, respectively. In contrast, the $\mathrm{H} 272 \mathrm{~L}$ mutation was detected at a frequency of $2.5 \%$ only in the 2009 population, whereas the $\mathrm{P} 225 \mathrm{~F}$ mutation was detected at a frequency of $7.5 \%$ only in the 2010 population.
\end{abstract} whereas, in another set of isolates, a nucleotide change from $A$ to $G$
Gray mold caused by Botrytis cinerea Pers. (teleomorph Botryotinia fuckeliana (de Bary) Whetzel) is one of the most important diseases of field- and greenhouse-grown vegetables, strawberry, ornamentals, grape, and fruit, causing significant yield losses (10). Control of the disease is mainly based on fungicide use, despite the fact that Botrytis cinerea represents a classical "high-risk" pathogen regarding the probability of resistance development. Some of the most serious problems of fungicide resistance were faced with this pathogen, including resistance to benzimidazoles, dicarboximides, anilinopyrimidines, hydroxyanilides, and quinone outside inhibitors (QoIs) due to target-site modifications $(17,23,24,29)$ or the recently reported mechanism of multidrug resistance (21).

Boscalid is a relatively new broad-spectrum fungicide belonging to the class of succinate dehydrogenase inhibitor (SDHI) fungicides. It is biologically active against different stages of fungal development but it primarily inhibits spore germination and elongation of germ tubes (32). Its activity spectrum includes several pathogens of important crop plants belonging to the Ascomycetes and Deuteromycetes.

Discovery and release into the market of boscalid opened a new perspective for this fungicide class and, recently, new molecules were developed for use in agriculture (13). Currently, the SDHI group of fungicides is divided into seven different chemical classes including 15 different molecules (12). They all share a common mode of action, consisting of the inhibition of the complex II in the mitochondrial respiratory chain, also known as succinate:quinone

Corresponding author: G. S. Karaoglanidis, E-mail: gkarao@agro.auth.gr

Accepted for publication 7 June 2011.

doi:10.1094/PDIS-04-11-0317

(c) 2011 The American Phytopathological Society oxidoreductase or succinate dehydrogenase (SDH; 8). The enzyme plays a crucial role in the tricarboxylic acid cycle and the mitochondrial electron transport chain, and its inhibition leads to a block of the cell energy production (27). The structure of complex II has been reviewed in several reports $(8,14,16)$. According to these reports, SDH consists of two parts, a soluble catalytic heterodimer and an integral membrane part. The former is composed of a hydrophilic flavoprotein (Fp), so called SDHFp or SDHA, and an iron-sulfur protein (Ip) subunit, so called SDHIp or SDHB, consisting of three iron-sulphur clusters: [2Fe-2S], [4Fe-4S], and [3Fe-4S]. The latter is composed of two hydrophobic polypeptides (SDHC and SDHD) that anchor the SDH complex to the inner membrane.

The risk for resistance development to SDHIs is considered to be high. Until now, field resistance to boscalid has been reported in several plant pathogens, including Alternaria alternata, Corynespora cassiicola, Didymella bryoniae, and Monilinia fructicola $(1,2,28,34)$. Furthermore, resistance to boscalid has also been reported in field strains of $B$. cinerea obtained from grape, strawberry, apple, and kiwifruit $(6,20,22,24,32)$. The mechanisms of resistance to SDHIs have been intensively investigated using either lab or field mutants of several fungi and have been recently reviewed by Avenot and Michailides (3). In recent studies exploring the mechanisms of resistance in boscalid-resistant $B$. cinerea field strains $(24,37)$ or in strains with laboratory-induced resistance $(9)$, six different amino acid changes in the SDHB subunit, three of which were species specific and one amino acid exchange in the SDHD subunit that was not species specific, were correlated with resistance to boscalid.

In Greece, boscalid was registered for use against gray mold on several crops, including strawberry in 2007. Based on the fact that strawberry fields in Greece are heavily treated with fungicides, the current study was initiated to (i) determine the levels of sensitivity to boscalid in isolates obtained from strawberry fields, (ii) investi- 
gate the mutations associated with resistance to boscalid, and (iii) develop a primer-introduced restriction analysis polymerase chain reaction (PIRA-PCR) method that enables the rapid detection of the mutations in resistant isolates.

\section{Materials and Methods}

Fungal isolates. Isolates of $B$. cinerea were collected from diseased strawberry fruit originating from the region of Pieria, northern Greece, one of the main strawberry production regions in the country. In this region, strawberry is cultivated as an annual crop. Sampling was carried out during three consecutive years (200810 ), at the end of the harvesting period when fungicide spray applications had been terminated. Each year, five strawberry fields were sampled by obtaining 5 to 10 diseased fruit from each field. The sampled fields had been sprayed with boscalid two to three times each year since 2007 . The isolation procedure was as previously described (29). In total, 42, 40, and 40 single-spore isolates were collected during 2008, 2009, and 2010, respectively. Amplification of the $\mathrm{Bc}-h c h$ locus was used to discriminate the isolates between group I (' $B$. pseudocinerea') and group II ( $B$. cinerea sensu stricto) (11). Determination of sensitivity to boscalid was performed just after the isolation and purification to single spores of the fungal strains each year. Until use, the isolates were maintained on potato dextrose agar slants at $4^{\circ} \mathrm{C}$.

Measurement of sensitivity to boscalid. Technical-grade boscalid (generously supplied by BASF, Limburgerhof, Germany) was dissolved in dimethyl sulfoxide to prepare stock solutions. Measurement of sensitivity to boscalid was performed on YBA medium (33) amended with $1.5 \%$ agar to solidify the medium and several fungicide concentrations $(0,0.005,0.01,0.05,0.1,0.5,1,5$, 10 , and $50 \mu \mathrm{g} \mathrm{ml}^{-1}$ ). Spore suspensions for each isolate were prepared in sterile distilled water at a concentration of $1 \times 10^{5} \mathrm{ml}^{-1}$. Aliquots of the conidial suspensions were spread on fungicideamended and fungicide-free $6-\mathrm{cm}$ petri dishes. For each combination of isolate and fungicide concentration, three replicate petri dishes were prepared. After $24 \mathrm{~h}$ of incubation at $20^{\circ} \mathrm{C}$, conidia were checked for germination and the germ tube length was measured in 20 spores per isolate and fungicide concentration. The fungicide concentration causing inhibition of germ tube growth by $50 \%$ ( $\mathrm{EC}_{50}$ value) of each isolate was calculated by plotting the relative inhibition of germ tube length against the $\log _{10}$ of fungicide concentrations in the three replicate dishes. Calculations were performed using SAS (JMP; SAS Institute, Cary, NC). Resistance factors (RFs) were calculated by dividing the $\mathrm{EC}_{50}$ value of each isolate with the mean $\mathrm{EC}_{50}$ value of the wild-type isolates. Isolates with RF values lower than 2 were considered sensitive and isolates with RF values ranging from 2 to 10,10 to 100 , and $>100$ were considered to have low, moderate, and high resistance, respectively.

DNA isolation. To extract DNA, all isolates were grown in potato dextrose broth (Sigma-Aldrich, St. Louis) for 2 days at $22^{\circ} \mathrm{C}$. The mycelium was harvested by filtration, dried, lyophilized, ground to a fine powder using micropestles (Eppendorf Interna- tional, Wesseling, Germany), and stored at $-20^{\circ} \mathrm{C}$ until use. DNA was extracted from 50 to $100 \mathrm{mg}$ of frozen mycelium using Puregene Core Kit A (Qiagen GmbH, Hilden, Germany) according to the manufacturer's protocol. DNA yield was estimated by gel electrophoresis and ethidium bromide staining.

$\boldsymbol{s d h} B$ amplification and sequencing. To identify the mutations correlated with resistance to boscalid, the complete coding sequences of the SDHB subunit of $25 \mathrm{~B}$. cinerea isolates, selected on the basis of their boscalid sensitivity, were compared with the corresponding gene sequence of the reference sensitive strain B05.10. (accession number BC1G_13286.1). Within the set of 25 isolates sequenced, 5 phenotypically sensitive isolates and 20 isolates exhibiting different levels of resistance to boscalid were included.

To amplify the entire $s d h B$ sequence, the primer pair IpBcBeg and IpBcEnd 2 described by Leroux et al. (24) was used (Table 1). Amplification conditions were performed like those described by Leroux et al. (24). PCR products were separated by electrophoresis in $1 \%$ agarose gel in $1 \times$ Tris-acetate-EDTA (TAE) buffer and visualized after ethidium bromide staining under UV light. PCR products were purified using NucleoSpin Extract II kit (MachereyNagel GmbH, Düren, Germany) and subsequently sequenced. Sequences were aligned using the computer software package Clustal W 2.0.9.

Mutation detection using PIRA-PCR. Sequence polymorphism analysis performed in the current study revealed that resistance to boscalid was associated with five different mutations located at codons 225 (P225F), 230 (N230I), and 272 (H272L/R/Y) of the SdhB subunit. For the detection of each of the five polymorphisms, a PIRA-PCR technique (15) was developed. For this purpose, a specific mismatched primer pair was designed for each mutation. Mismatches were selected to artificially create HindIII, BamHI, BglII, HhaI, and EcoRV restriction sites during PCR to detect P225F, N230I, H272L, H272R, and H272Y mutations, respectively. Mismatched primers, enzymes, and enzyme restriction sites are summarized in Table 1.

PCR reactions were conducted in a $20-\mu \mathrm{l}$ reaction volume containing 10 to $20 \mathrm{ng}$ of genomic DNA, $2 \mu \mathrm{l}$ of buffer $(10 \times), 2 \mu \mathrm{l}$ of dNTPS $(2 \mathrm{mM}), 1 \mu \mathrm{l}$ of Taq $(1 \mathrm{U})$, and $0.5 \mu \mathrm{l}$ of each primer $(10$ pmol). Amplification conditions were similar for all five primer pairs, as follows: $94^{\circ} \mathrm{C}$ for $5 \mathrm{~min}$; followed by 30 cycles of $30 \mathrm{~s}$ at $94^{\circ} \mathrm{C}, 30 \mathrm{~s}$ at $55^{\circ} \mathrm{C}$, and $30 \mathrm{~s}$ at $72^{\circ} \mathrm{C}$; and finally $2 \mathrm{~min}$ at $72^{\circ} \mathrm{C}$. PCR products were separated by electrophoresis in $2 \%$ agarose gel in $1 \times$ TAE buffer and visualized after ethidium bromide staining under UV light.

PCR products amplified by the primer pairs P225F-fw/P225-rev, N230I-fw/N230I-rev, H272L-fw/H272-rev, H272R-fw/H272-rev, and H272Y-fw/H272-rev were digested with the enzymes HindIII, BamHI, BglII, HhaI, and EcoRV, respectively. Digestion solutions consisted of $5 \mu$ l of PCR product, 0.5 unit of each enzyme, and 1 unit of the respective enzyme buffer, in a total reaction volume of $10 \mu$ l. Digestions were performed overnight at $37^{\circ} \mathrm{C}$. The entire

Table 1. List of primers used in the study to amplify $s d h B$ of Botrytis cinerea and partial $s d h B$ sequences containing mutations associated with boscalid resistance for primer-introduced restriction analysis polymerase chain reaction detection of the mutations

\begin{tabular}{|c|c|c|c|c|c|}
\hline Primer & Sequence $\left(5^{\prime}-3^{\prime}\right)^{\mathrm{a}}$ & Amplified fragment (bp) & Restriction site & Enzyme & Target \\
\hline $\mathrm{IpBcBeg}^{\mathrm{b}}$ & ССАСТССТCCATAATGGCTGCTCTCCGC & 953 & $\ldots$ & $\ldots$ & $\operatorname{sdh} B$ \\
\hline IpBecEnd $2^{\mathrm{b}}$ & CTCATCAAGCCCСCTCATTGATATC & & ... & & \\
\hline H272L-fw & GGCAGCTTTGGATAACAGCATGAGTTTGTACAGAGATC & 120 & A $\boldsymbol{\nabla G A T C T}$ & $B g l \mathrm{II}$ & $\mathrm{H} 272 \mathrm{~L}$ \\
\hline H272R-fw & GGCAGCTTTGGATAACAGCATGAGTTTGTACAGATGGC & 120 & GCG $\nabla \mathrm{C}$ & HhaI & $\mathrm{H} 272 \mathrm{R}$ \\
\hline H272Y-fw & GGCAGCTTTGGATAACAGCATGAGTTTGTACAGATAT & 120 & GAT $\nabla$ ATC & EcoRV & $\mathrm{H} 272 \mathrm{Y}$ \\
\hline $\mathrm{H} 272-\mathrm{rev}^{\mathrm{c}}$ & GCCATTTCCTTCTTAАTCTCCGC & & & & $\mathrm{H} 272 \mathrm{~L} / \mathrm{R} / \mathrm{Y}$ \\
\hline N230I-fw & GACCCAGCACCAGAAGGAAAAG & 150 & G $\nabla$ GATCC & BamHI & $\mathrm{N} 230 \mathrm{I}$ \\
\hline N230I-rev & GATAGCTGGTCCCAAGTACTCCTCACGG & & $\ldots$ & & \\
\hline P225F-fw & GTATTCTCTGCGCATGCTGCTCGACATCAAGC & 144 & A $\boldsymbol{\nabla A G C T T}$ & HindIII & $\mathrm{P} 225 \mathrm{~F}$ \\
\hline P225-rev & AAGCTGCCTTACGTTCTTCC & $\ldots$ & $\ldots$ & $\ldots$ & $\ldots$ \\
\hline
\end{tabular}

\footnotetext{
${ }^{a}$ Letters in bold indicate the nucleotide mismatches.

${ }^{b}$ Primers developed by Leroux et al. (24).

${ }^{\mathrm{c}}$ A common reverse primer was used for the detection of mutations located at codon 272 of $s d h B$.
} 
boscalid-resistant subpopulation, including isolates of known mutations after sequencing, was screened with the PIRA-PCR primers to validate the method and to identify the mutations in isolates that had not been sequenced.

\section{Results}

Sensitivity to boscalid. All of the isolates used in the current study were group II isolates (data not shown). Among the 42 isolates collected and tested in 2008, 15 (35\%) were found to be moderately resistant to boscalid (Fig. 1). Resistance frequencies increased during the two following years. Sensitivity measurements of the 2009 population $(n=40)$ revealed that 19 isolates (47.5\%) were moderately resistant to boscalid and 1 isolate exhibited a high level of resistance. In the 2010 population $(n=40), 20$ (50\%) moderately resistant isolates and $3(7.5 \%)$ highly resistant isolates were found. $\mathrm{EC}_{50}$ values of all sensitive isolates ranged from 0.05 to $0.21 \mu \mathrm{g} \mathrm{ml}^{-1}$, while isolates with moderate levels of resistance had $\mathrm{EC}_{50}$ values ranging from 1.37 to $7.79 \mu \mathrm{g} \mathrm{ml} \mathrm{m}^{-1}$. Highly resistant isolates showed $\mathrm{EC}_{50}$ values higher than $50 \mu \mathrm{g} \mathrm{ml}^{-1}$ (Fig. 1)

$s d h B$ sequence analysis of boscalid-sensitive and -resistant strains. In total, five single-nucleotide substitutions in $s d h B$ were detected in the 25 isolates sequenced. Two of the mutations were located at codons 225 and 230, in the third exon of the gene. Three isolates collected during 2010 showed nucleotide changes from CC to TT at codon 225, resulting in the substitution of proline by phenylalanine $(\mathrm{P} 225 \mathrm{~F})$. Three boscalid-resistant isolates showed a nucleotide change from $\mathrm{A}$ to $\mathrm{T}$ at codon 230 , resulting in the

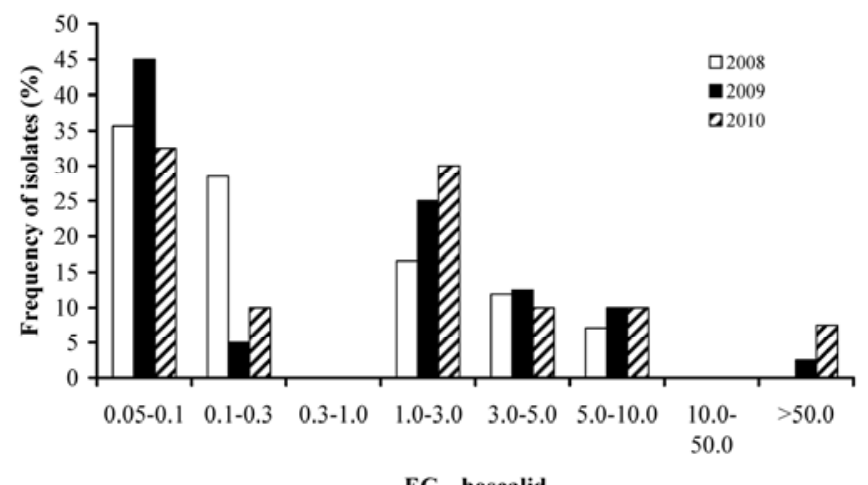

Fig. 1. Distribution of fungicide concentrations causing inhibition of germ tube growth by $50 \%$ ( $\mathrm{EC}_{50}$ values) to boscalid in Botrytis cinerea isolates collected from strawberry fields in Greece during $2008(n=42), 2009(n=40)$, and $2010(n=40)$. substitution of the asparagine by isoleucine (N230I). The remaining three mutations revealed in our study were found at codon 272 , which is located in the second cysteine-rich cluster of the SDHB subunit. Eight isolates showed a nucleotide change from $\mathrm{C}$ to $\mathrm{T}$ at codon 272 , resulting in the substitution of histidine by arginine (H272R), while five isolates showed a nucleotide change from A to $\mathrm{G}$, resulting in the substitution of histidine by tyrosine (H272Y). A single isolate collected in 2009 showed a nucleotide change from A to $\mathrm{T}$ at codon 272 , resulting in the substitution of histidine by leucine (H272L). No nucleotide polymorphisms in $s d h B$ were observed in any of the boscalid-sensitive isolates sequenced. The location of the boscalid resistance-related mutations within $s d h \mathrm{~B}$ is shown in Figure 2.

Detection of $\boldsymbol{s} d \boldsymbol{h} B$ mutations using PIRA-PCR. PCR products were amplified with the PIRA-PCR primer pair P225F-fw/P225rev and digested with HindIII. In isolates possessing the P225F mutation, this resulted in two fragments of 116 and $28 \mathrm{bp}$ whereas, in the case of isolates without this specific mutation, the PCR product remained undigested (Fig. 3A). Similarly, PCR products amplified with the PIRA-PCR primer pair N230I-fw/N230I-rev and digested with BamHI resulted in two fragments of 119 and $31 \mathrm{bp}$ only with isolates possessing the N230I mutation whereas, with isolates lacking this mutation, the PCR product remained undigested (Fig. 3B). PCR reactions with the forward primers H272Lfw, H272R-fw, and H272Y-fw and the common reverse primer H272-rev all amplified a 120-bp product. Digestion of the PCR products amplified by primer pair H272L-fw/H272-rev with $B g l \mathrm{II}$ resulted in two fragments of 85 and 35 bp only for the isolate possessing the H272L mutation (Fig. 4A). Digestion of PCR products amplified by primer pair H272R-fw/H272-rev with HhaI resulted in two fragments of 85 and $35 \mathrm{bp}$ only for isolates possessing the H272R mutation (Fig. 4B). Finally, digestion of the PCR products amplified by primer pair $\mathrm{H} 272 \mathrm{Y}-\mathrm{fw} / \mathrm{H} 272-\mathrm{rev}$ with EcoRV resulted in two fragments of 85 and $35 \mathrm{bp}$ only for the isolates that did not possess the $\mathrm{H} 272 \mathrm{Y}$ mutation whereas, in isolates with the $\mathrm{H} 272 \mathrm{Y}$ mutation, the PCR products remained undigested (Fig. 5).

Frequency of $s d h B$ mutations and their correlations to boscalid sensitivity phenotypes. Our entire boscalid-resistant subpopulation was screened using the PIRA-PCR technique to identify the mutations associated with resistance. Results showed that $\mathrm{H} 272 \mathrm{R}$ was the predominant mutation associated with resistance to boscalid, with frequencies of $28.5,37.5$, and $30 \%$ for the 2008, 2009, and 2010 populations, respectively (Table 2). The $\mathrm{H} 272 \mathrm{Y}$ mutation was present at frequencies of $7.1 \%$ (2008), $5 \%$ (2009), and $10 \%$ (2010) of the isolates. Only one isolate collected during 2009 was found to possess the H272L mutation (Table 2). The N230I mutation was absent during the first year of sampling

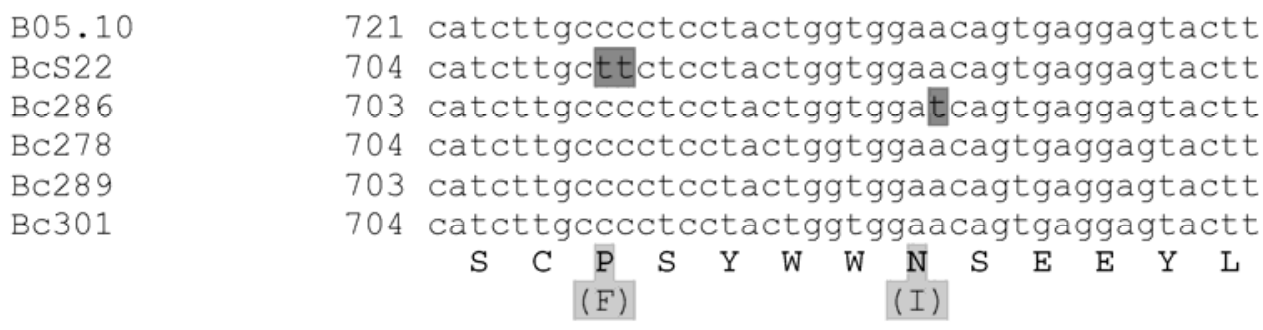

B05. 10

$\operatorname{BcS} 22$

$\mathrm{BC} 286$

$\mathrm{BC} 278$

Bc289

$\mathrm{BC} 301$
841 tggataacagcatgagtttgtacagatgtcacactattct
823 tggataacagcatgagtttgtacagatgtcacactattct
823 tggataacagcatgagtttgtacagatgtcacactattct
823 tggataacagcatgagttgtacagatgtctcactatct
823 tggataacagcatgagtttgtacagatgtcagactattct
824 tggataacagcatgagtttgtacagatgttacactattct

$\begin{array}{llllllllllllllll}D & N & S & M & S & L & Y & R & C & H & T & I & L\end{array}$
223

Fig. 2. Partial nucleotide and deduced amino acid sequence of $s d h B$ in boscalid-sensitive and boscalid-resistant Botrytis cinerea isolates. B05.10 is the reference sensitive isolate. Shadowed regions show nucleotide substitutions. Letters in parentheses show the amino acid substitutions. 
(2008); however, two isolates with the N230I mutation were found in 2009 and three isolates in 2010, accounting for 5 and $7.5 \%$ of the isolates tested, respectively. The mutation P225F was identified only in three isolates ( $7.5 \%$ of the isolates tested) collected in 2010 (Table 2).

Identification of the $s d h B$ mutations by either direct sequencing or PIRA-PCR allowed the grouping of the isolates according to their levels of sensitivity to boscalid (Table 2). Isolates lacking mutations showed $\mathrm{EC}_{50}$ values ranging from 0.05 to $0.21 \mu \mathrm{g} \mathrm{ml}^{-1}$ (mean value of $0.11 \mu \mathrm{g} \mathrm{ml} \mathrm{m}^{-1}$ ). The 39 isolates possessing the $\mathrm{H} 272 \mathrm{R}$ mutation showed $\mathrm{EC}_{50}$ values ranging from 1.37 to $7.28 \mu \mathrm{g}$ $\mathrm{ml}^{-1}$ (RFs $=14$ to 73 ). The nine isolates possessing the $\mathrm{H} 272 \mathrm{Y}$ mutation showed $\mathrm{EC}_{50}$ values ranging from 1.57 to $7.79 \mu \mathrm{g} \mathrm{ml}^{-1}$ $(\mathrm{RFs}=16$ to 78$)$. The five isolates possessing the N230I mutation showed $\mathrm{EC}_{50}$ values ranging from 2.21 to $5.96 \mu \mathrm{g} \mathrm{ml}^{-1}$ ( $\mathrm{RFs}=22$ to 60 ). The only isolate containing the H272L mutation and the three isolates containing the $\mathrm{P} 225 \mathrm{~F}$ mutation all showed an $\mathrm{EC}_{50}$ value higher than $50 \mu \mathrm{g} \mathrm{ml}^{-1}(\mathrm{RF}>500)$, which was the highest dose tested.

\section{Discussion}

The survey of $B$. cinerea populations from one of the main strawberry production regions in Greece for resistance to the SDHI fungicide boscalid conducted for three consecutive years showed a widespread presence of resistant phenotypes. Boscalid-resistant strains emerged only 2 years after the introduction of SDHIs for agricultural use. In the sampled region, strawberry fields were heavily treated with more than six fungicide sprays applied from the beginning of the flowering period (early March) until late May, leading to high selection pressure. Currently, field resistance of $B$. cinerea to boscalid has been reported in a limited number of hosts, including grape in Germany and France $(22,24)$, strawberry in Germany (32), apple fruit in Washington State (20), and kiwifruit in Greece (6).

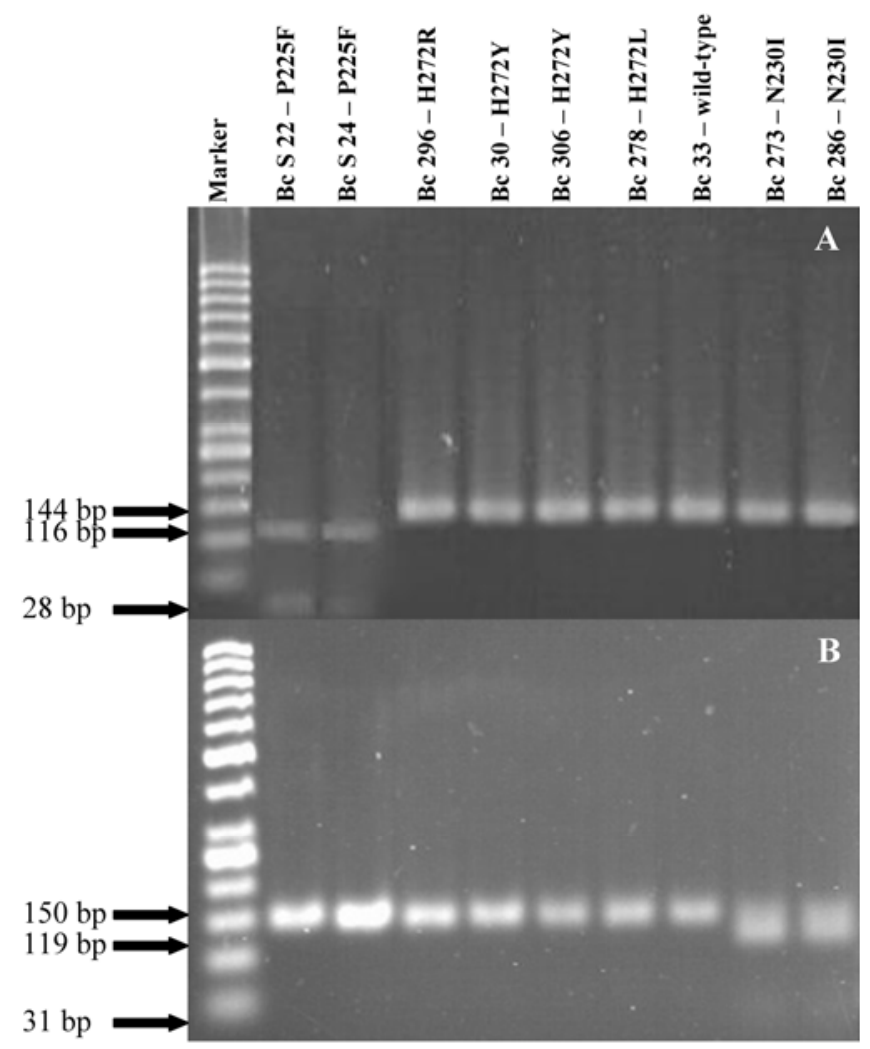

Fig. 3. Detection of the $\mathbf{A}, \mathrm{P} 225 \mathrm{~F}$ mutation and $\mathbf{B}, \mathrm{N} 230 \mathrm{l}$ mutation in the $\operatorname{sdh} B$ subunit gene of Botrytis cinerea isolates from strawberry. A, Hindlll digestion fragments from isolates possessing the P225F mutation yielded fragments of 116 and $28 \mathrm{bp} ; \mathrm{B}, \mathrm{BamHI}$ digestion fragments from isolates possessing the N230I mutation yielded fragments of 119 and $31 \mathrm{bp}$.
Sequencing of boscalid-resistant strains revealed the presence of five independent mutations located in the iron-sulfur protein (SDHB subunit) of the mitochondrial SDH. The SDHB subunit is highly conserved among both eukaryotes and prokaryotes, whereas there is much greater sequence variation in the two membranespanning subunits (SDHC and SDHD; 8). Three mutations in SDHB (H272Y, H272R, and H272L) have been previously described in two recent reports for $B$. cinerea isolates obtained from grape or strawberry in France and Germany $(24,32)$. The presence of the $\mathrm{H} 272 \mathrm{Y} / \mathrm{R}$ mutations was also detected in $B$. cinerea

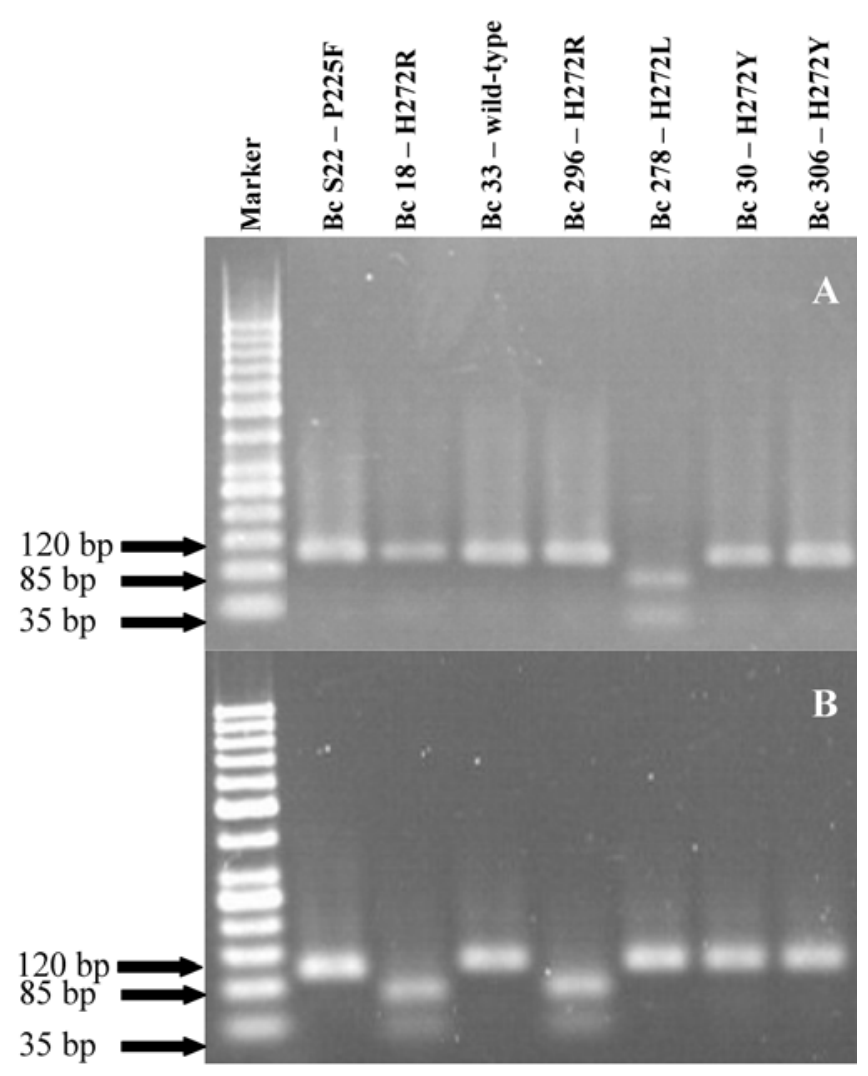

Fig. 4. Detection of $\mathbf{A}, \mathrm{H} 272 \mathrm{~L}$ and $\mathbf{B}, \mathrm{H} 272 \mathrm{R}$ mutations in $s d h B$ of Botrytis cinerea isolates from strawberry. A, Bg/ll digestion fragments from an isolate possessing the H272L mutation yielded fragments of 85 and $35 \mathrm{bp} ; \mathbf{B}$, Hhal digestion fragments from isolates possessing the H272R mutation yielded fragments of 85 and $35 \mathrm{bp}$.

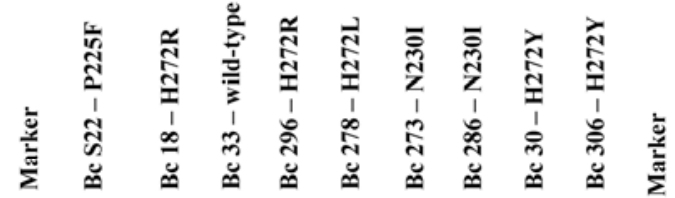

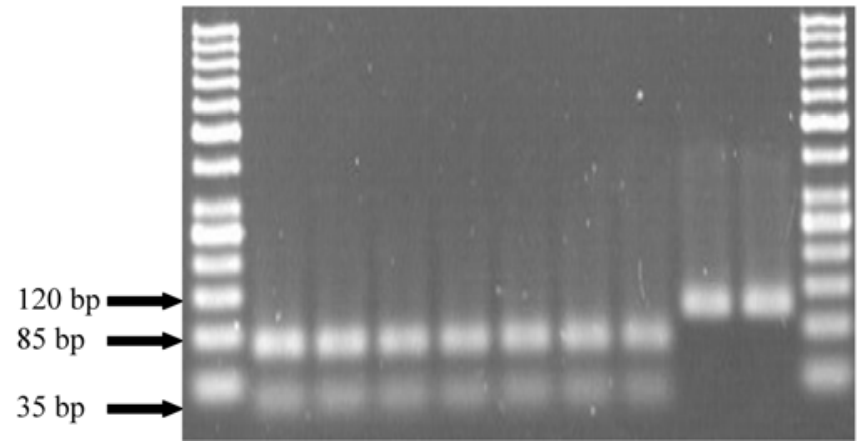

Fig. 5. Detection of $\mathrm{H} 272 \mathrm{Y}$ mutation in $s d h B$ of Botrytis cinerea isolates from strawberry. EcoRV digestion fragments from isolates that do not possess the $\mathrm{H} 272 \mathrm{Y}$ mutation yielded fragments of 85 and $35 \mathrm{bp}$. 
boscalid-resistant population from apple in the United States (37). Mutations at the corresponding histidine codon were previously shown to be the predominant mutations associated with resistance to SDHIs in several phytopathogenic fungi. Those include the $\mathrm{H} 267 \mathrm{Y} / \mathrm{L}$ in Mycosphaerella graminicola (31), H257Y/L in Ustilago maydis $(7,19)$, and $\mathrm{H} 278 \mathrm{Y} / \mathrm{R}$ in Corynespora cassiicola (28). Replacements of histidine by either threonine or tyrosine at codon $277(\mathrm{H} 277 \mathrm{R} / \mathrm{Y})$ have also been associated with resistance to boscalid in A. alternata isolates from pistachio (4) but, in this pathogen, the predominant mutation associated with resistance to boscalid was located at codon 134 in SDHC (H134R) (5). The location of these histidine mutations corresponds to one of the two ubiquinone binding sites ( $\mathrm{Qp}$ site) that has been determined to be close to the third iron-sulfur complex [3Fe-4S] in the SDHB subunit (35). The mutations cause structural changes at the subunit and, consequently, do not allow the binding of the fungicide to the ubiquinone binding site. The precise ubiquinone binding sites have been extensively studied in yeast and bacterial mitochondrial SDHs and have been found to be several amino acid residues located in SDHB, SDHC, and SDHD subunits $(30,36)$.

The fourth mutation revealed in the current study was a proline replacement by phenylalanine $(\mathrm{P} 225 \mathrm{~F})$, which correlated with very high levels of resistance to boscalid. The same mutation has previously been reported in $B$. cinerea isolates from grape in Germany (32) and from apple in the United States (37). Two more mutations at this codon (P225T and P225L) were recently reported in France, in strains with moderate and high levels of resistance, respectively, to boscalid (24). The fifth mutation revealed in the current study was N230I, which correlated with moderate levels of resistance to boscalid. The same mutation was also found by Leroux et al. (24) in one isolate in their samples from grape. The proline and asparagine residues found to be mutated (P225F and N230I) belong to the same highly conserved amino acid motif of the second ironsulfur complex [4Fe-4S] of the SDHB subunit (14). The tryptophane residues located between the proline and asparagine residues in that motif have been shown to be part of the ubiquinone binding site (16). All of these mutations have not been described yet in any fungal species other than $B$. cinerea and currently seem to be species specific.

In conclusion, in the Greek strawberry population tested, five SDH mutations have been revealed whereas, in the two recent reports by Leroux et al. (24) and Stammler et al. (32), seven and four different mutations, respectively, were associated with resistance to boscalid in field isolates of $B$. cinerea. Furthermore, in our tested population, the predominant mutation was the H272R, with frequencies ranging from 28.5 to $37.5 \%$, whereas, in the French grape population, the predominant mutation was H272Y (24). Whether these differences account for the fact that our sample was restricted in just one crop (strawberry) in one region of Greece (Pieria region), or whether they reflect differences in the genetic background of fungal populations in Greece compared with populations in central-western Europe, remains to be clarified. In addition, the differences in the frequency of mutations revealed in the current study are still unexplained. As previously mentioned, H272R was the predominant mutation while mutations conferring high levels of resistance were found in lower frequencies. Such differences in mutation frequencies may account for differences in the fitness of the mutated strains, their survival and competitive ability in the field, the fungicide spray schedules, and the application doses. Further investigations are required to clarify these aspects.

The results of the current study suggested that, despite a certain degree of variability, the two most commonly found mutations ( H272R and H272Y) were usually associated with moderate levels of resistance to boscalid (RF values of 14 to 73 and 16 to 78 , respectively). This finding is in agreement with that of Leroux et al. (24), who also found that these two mutations were correlated with moderate levels of resistance to boscalid (RF values of 40 to 44). De Miccolis et al. (9) found that $B$. cinerea laboratory mutants possessing the $\mathrm{H} 272 \mathrm{Y}$ mutation showed low levels of resistance to boscalid. However, in another recent study, isolates carrying $\mathrm{H} 272 \mathrm{Y} / \mathrm{R}$ mutations were found to have a greater phenotypic variability, ranging from low to high resistance levels (37). Whether genetic or methodological variability accounts for these differences deserves further investigation. In our study, a limited number of three and one isolates possessing the P225F and H272L mutations, respectively, were all found to be highly resistant to boscalid, in agreement with the findings of Leroux et al. (24) and Yin et al. (37). However, in all these studies, isolates possessing the P225F and H272L mutations were only rarely found, which does not allow a definite conclusion on the effects of these mutations. Future monitoring data from several hosts and regions could contribute to our understanding of the effect of these mutations on the sensitivity to SDHIs and the rate of their spread in boscalid-treated fields.

Several molecular methods have been developed in the past for the quick detection of fungicide resistance, such as PCR restriction fragment length polymorphism and allele-specific PCR and pyrosequencing (26). PIRA-PCR has also been used for the rapid detection of carbendazim-resistant strains of Fusarium graminearum (25) and capropamide-resistant strains of Magnaporthe grisea (18). In the current study. PIRA-PCR was used for rapid detection of N230I, P225F, and H272L/R/Y mutations located in the SDHB subunit of boscalid-resistant isolates of $B$. cinerea. The PIRA-PCR primer pairs correctly genotyped each of the five mutated codons in the SDHB subunit. Obviously, the development of primers for additional SDH mutations that have already been described in field or laboratory isolates of $B$. cinerea would be a significant contribution toward quicker detection of resistance in this promising fungicide class, and facilitate the evaluation of antiresistance strategies.

The development of resistance to SDHIs in B. cinerea populations is expected to cause significant problems for disease management because $s d h$ mutations may strongly affect the fungicide performance against resistant strains. Furthermore, resistance to older botryticides such as benzimidazoles, dicarboximides, and anilinopyrimidines is already widespread, and dual resistance of the pathogen to SDHIs and the newly introduced QoIs is also a very common trait $(6,20,24)$. Maintaining the high efficacy of boscalid or other compounds belonging to the SDHI group that will be delivered into the market in the near future is a prerequisite for successful disease management because alternative fungicides are restricted in number. A better understanding of factors that may affect the evolution of SDHIs resistance in $B$. cinerea, such as the effect of each specific mutation on the fitness of the strains or on

Table 2. Association of amino acid substitutions in the $s d h \mathrm{~B}$ gene with sensitivity levels to boscalid in Botrytis cinerea isolates from strawberry

\begin{tabular}{|c|c|c|c|c|c|}
\hline \multirow[b]{2}{*}{ Mutation } & \multicolumn{2}{|c|}{ Range of } & \multicolumn{3}{|c|}{ Number of isolates ${ }^{a}$} \\
\hline & $\mathrm{EC}_{50}\left(\mu \mathrm{g} \mathrm{ml}^{-1}\right)^{\mathrm{b}}$ & Resistance factor $^{c}$ & $2008(n=42)$ & $2009(n=40)$ & $2010(n=40)$ \\
\hline Sensitive strains & $0.05-0.21$ & $0.5-2.0$ & $27(64.2)$ & $20(50)$ & $18(45)$ \\
\hline $\mathrm{H} 272 \mathrm{R}$ & $1.37-7.28$ & $14-73$ & $12(28.5)$ & $15(37.5)$ & $12(30)$ \\
\hline $\mathrm{H} 272 \mathrm{Y}$ & $1.57-7.79$ & $16-78$ & $3(7.1)$ & $2(5)$ & $4(10)$ \\
\hline $\mathrm{N} 230 \mathrm{I}$ & $2.21-5.96$ & $22-60$ & $0(0)$ & $2(5)$ & $3(7.5)$ \\
\hline $\mathrm{H} 272 \mathrm{~L}$ & $>50$ & $>500$ & $0(0)$ & $1(2.5)$ & $0(0)$ \\
\hline $\mathrm{P} 225 \mathrm{~F}$ & $>50$ & $>500$ & $0(0)$ & $0(0)$ & $3(7.5)$ \\
\hline
\end{tabular}

a Numbers in parentheses show the values in percentage of total population.

${ }^{\mathrm{b}} \mathrm{EC}_{50}$ value = fungicide concentration causing inhibition of germ tube growth by $50 \%$.

${ }^{\mathrm{c}}$ Resistance factors were calculated by dividing the $\mathrm{EC}_{50}$ value of the resistant isolates by the mean $\mathrm{EC}_{50}$ value of the wild-type isolates of $0.1 \mu \mathrm{g} \mathrm{ml}^{-1}$. 
the cross-resistance relationships among the different members of the SDHI group, remains a goal for future research.

\section{Acknowledgments}

We thank BASF Hellas S.A. for providing pure technical grade of boscalid. G. S. Karaoglanidis was financially supported by a DAAD scholarship.

\section{Literature Cited}

1. Amiri, A., Brannen, P. M., and Schnabel, G. 2010. Reduced sensitivity in Monilinia fructicola field isolates from South Carolina and Georgia to respiration inhibitor fungicides. Plant Dis. 94:737-743.

2. Avenot, H. F., and Michailides, T. J. 2007. Resistance to boscalid fungicide in Alternaria alternata isolates from pistachio in California. Plant Dis. 91:1345-1350.

3. Avenot, H. F., and Michailides, T. J. 2010. Progress in understanding molecular mechanisms and evolution of resistance to succinate dehydrogenase inhibiting (SDHI) fungicides in phytopathogenic fungi. Crop Prot. 29:643651 .

4. Avenot, H. F., Sellam, A., Karaoglanidis, G., and Michailides, T. J. 2008. Characterization of mutations in the iron-sulphur subunit of succinate dehydrogenase correlating with boscalid resistance in Alternaria alternata from California pistachio. Phytopathology 98:736-742.

5. Avenot, H. F., Sellam, A., and Michailides, T. J. 2009. Characterization of mutations in the membrane-anchored subunits AaSDHC and AaSDHD of succinate dehydrogenase from Alternaria alternata isolates conferring field resistance to the fungicide boscalid. Plant Pathol. 58:1134-1143.

6. Bardas, G. A., Veloukas, T., Koutita, O., and Karaoglanidis, G. S. 2010. Multiple resistance of Botrytis cinerea from kiwifruit to SDHIs, QoIs and fungicides of other chemical groups. Pest Manage. Sci. 66:967-973.

7. Broomfield, P. L. E., and Hargreaves, J. A. 1992. A single amino-acid change in the iron-sulphur protein subunit of succinate dehydrogenase confers resistance to carboxin in Ustilago maydis. Curr. Genet. 22:117-121.

8. Cecchini, G. 2003. Function and structure of complex II of the respiratory chain. Annu. Rev. Biochem. 72:77-109.

9. De Miccolis Angelini, R. M., Habib, W., Rotolo, C., Pollastro, S., and Faretra, F. 2010. Selection, characterization and genetic analysis of laboratory mutants of Botryotinia fuckeliana (Botrytis cinerea) resistant to the fungicide boscalid. Eur. J. Plant Pathol. 128:185-199.

10. Elad, Y., Williamson, B., Tudzynski, P., and Delen, N. 2004. Botrytis spp. and diseases they cause in agricultural ecosystems - an introduction. Pages 1-8 in: Botrytis: Biology, Pathology and Control. Y. Elad, B. Williamson, P. Tudzynski, and N. Delen, eds. Springer, Dordrecht, The Netherlands.

11. Fournier, E., Levis, C., Fortini, D., Leroux, P., Giraud, T., and Brygoo, Y. 2003. Characterization of $\mathrm{Bc}-h c h$, the Botrytis cinerea homolog of the Neurospora crassa het-c vegetative incompatibility locus, and its use as a population marker. Mycologia 95:251-261.

12. FRAC (Fungicide Resistance Action Committee) 2011. The FRAC list of fungicide common names. www.frac.info.

13. Glättli, A., Stammler, G., Grote, T., and Schlehuber, S. 2010. SDH Inhibitors: History, biological performance and molecular mode of action. In: Modern Fungicides and Antifungal Compounds, 16th Int. Reinhardsbrunn Symp.

14. Hagerhall, C. 1997. Succinate: quinone oxidoreductases variations in a conserved theme. Biochem. Biophys. Acta 1320:107-141.

15. Haliassos, A., Chomel, J. C., Grandjouan, S., Kruh, J., Kaplan, J. C., and Kitzis, A. 1989. Detection of minority point mutations by modified PCR technique: a new approach for a sensitive diagnosis of tumor-progression markers. Nucleic Acids Res. 17:8093-8099.

16. Horsefield, R., Yankovskaya, V., Sexton, G., Whittingham, W., Shiomi, K., Omura, S., Byrne, B., Cecchini, G., and Iwata, S. 2006. Structural and computational analysis of the quinone-binding site of complex II (succinate-ubiquinone oxidoreductase) - a mechanism of electron transfer and proton conduction during ubiquinone reduction. J. Biol. Chem. 281:7309-7316.

17. Ishii, H., Fountaine, J., Chung, W.-H., Kansako, M., Nishimura, K., Takahashi, K., and Oshima, M. 2009. Characterisation of QoI-resistant and field isolates of Botrytis cinerea from citrus and strawberry. Pest Manage. Sci. 65:916-922.

18. Kaku, K., Takagaki, M., Shimizu, T., and Nagayama, K. 2003. Diagnosis of dehydratase inhibitors in melanin biosynthesis inhibitor (MBID) resistance by primer-introduced restriction enzyme analysis in scytalone dehydratase gene of Magnaporthe grisea. Pest Manage. Sci. 59:843-846.

19. Keon, J. P. R., White, G. A., and Hargreaves, J. A. 1991. Isolation, characterization and sequence of a gene conferring resistance to the systemic fungicide carboxin from the maize smut pathogen, Ustilago maydis. Curr. Genet. 19:475-481

20. Kim, Y. K., and Xiao, C. L. 2010. Resistance to pyraclostrobin and boscalid in populations of Botrytis cinerea from stored apples in Washington State. Plant Dis. 94:604-612.

21. Kretschmer, M., Leroch, M., Mosbach, A., Walker, A.-S., Filinger, S., Mernke, D., Schoonbeek, H., Pradier, J., Leroux, P., DeWaard, M., and Hahn, M. 2009. Fungicide-driven evolution and molecular basis of multidrug resistance in field populations of the grey mould fungus Botrytis cinerea. PLoS Path. 5(12):e1000696.

22. Leroch, M., Kretchmer, M., and Hahn, M. 2011. Fungicide resistance phenotypes of Botrytis cinerea isolates from commercial vineyards in South West Germany. J. Phytopathol. 159:63-65.

23. Leroux P, 2004. Chemical control of Botrytis and its resistance to chemical fungicides. Pages 195-222 in: Botrytis: Biology, Pathology and Control. Y. Elad, B. Williamson, P. Tudzynski, and N. Delen, eds. Springer, Dordrecht, The Netherlands

24. Leroux, P., Gredt, M., Leroch, M., and Walker A.-S. 2010. Exploring mechanisms of resistance to respiratory inhibitors in field strains of Botrytis cinerea, the causal agent of gray mold. Appl. Environ. Microbiol. 76:66156630.

25. Luo, Q. Q., Xu, J. Q., Hou, Y. P., Chen, C. J., Wang, J. X., and Zhou, M. G. 2009. PIRA-PCR for detection of Fusarium graminearum genotypes with moderate resistance to carbendazim. Plant Pathol. 58:882-887.

26. Ma, Z., and Michailides, T. J. 2005. Advances in understanding molecular mechanisms of fungicide resistance and molecular detection of resistant genotypes in phytopathogenic fungi. Crop Prot. 24:853-863.

27. Matsson, M., and Hederstedt, L. 2001. The carboxin-binding site on Paracoccus denitrificans succinate:quinone reductase identified by mutations. J. Bioenerg. Biomembr. 33:99-105.

28. Miyamoto, T., Ishii, H., Stammler, G., Koch, A., Ogawara, T., Tomita, Y., Fountaine, J.M., Ushio, S., Seko, T., and Kobori, S. 2010. Distribution and molecular characterization of Corynespora cassiicola isolates resistant to boscalid. Plant Pathol. 59:873-881.

29. Myresiotis, C. K., Karaoglanidis, G. S., and Tzavella-Klonari, K. 2007. Monitoring for resistance of Botrytis cinerea isolates from vegetable crops to anilinopyrimidine, phenylpyrrole, hydroxyanilide, benzimidazole and dicarboximide fungicides. Plant Dis. 91:407-413.

30. Oyedotum, K. S., and Lemire, B. D. 2001. The quinone-binding sites of the Saccharomyces cerevisiae succinate-ubiquinone oxidoreductase. J. Biol. Chem. 276:16936-16943.

31. Skinner, W., Bailey, A., Renwick, A., Keon, J., Gurr, S., and Hargreaves, S. 1998. A single-amino-acid substitution in the iron-sulphur protein subunit of succinate dehydrogenase determines resistance to carboxin in $M y$ cosphaerella graminicola. Curr. Genet. 34:393-398.

32. Stammler, G., Brix, H. D., Nave, B., Gold, R., and Schoefl, U. 2008. Studies on the biological performance of boscalid and its mode of action. Pages 45-51 in: Modern Fungicides and Antifungal Compounds V. H. W. Dehne, H. B. Deising, U. Gisi, P. E. Russell, and H. Lyr, eds. Deutsche Phytomedizinische Gesellschaft, Braunschweig, Germany.

33. Stammler, G., and Speakman, J. 2006. Microtiter method to test the sensitivity of Botrytis cinerea to boscalid. J. Phytopathol. 154:508-510.

34. Stevenson, K. L., Langston, D. B., and Sanders, F. 2008. Baseline sensitivity and evidence of resistance to boscalid in Didymella bryoniae. (Abstr.) Phytopathology 98:S151.

35. Sun, F., Huo, X., Zhai, Y., Wang, A., Xu, J., Su, D., Bartlam, M., and Rao, Z. 2005. Crystal structure of mitochondrial respiratory membrane protein complex II. Cell 121:1043-1057.

36. Yankovskaya, V., Horsefield, R., Tornroth, S., Luna-Chavez, C., Miyoshi, H., Leger, C., Byrne, B., Cecchini, G., and Iwata, S. 2003. Architecture of succinate dehydrogenase and reactive oxygen species generation. Science 299:700-704

37. Yin, Y. N., Kim, Y. K., and Xiao, C. L. 2011. Molecular characterization of boscalid resistance in field isolates of Botrytis cinerea from apple. Phytopathology 101:986-995. 